\title{
GEOGRAFIA E PLANEJAMENTO: ENTRE O PURO E O APLICADO
}

\author{
Cássio Eduardo Viana Hissa(*)
}

\begin{abstract}
The objective of this study is to present some introductory ideas about concepts concerning planning. The text is meant to motivate discussions about preliminary notions referring to the concepts in question. Geography is taken as an area of knowledge which, traditionally, turns next to the practices related to the urban and regional planning. This paper also proposes a discussion about the nature of the relationships and boundaries stablished between what can be called pure ou applied. It is only a start point which can, later on, amplifly the improvement of the organization of criteria, priorities and strategies which surround planning practices.
\end{abstract}

\section{INTRODUÇÃO}

O puro pode ser compreendido como aquilo que não foi tocado. Na linguagem da ciência, o puro qualifica aquilo que não foi produzido para transformar, para ser aplicado. Com o progressivo estabelecimento da ciência moderna, a fronteira entre o puro e o aplicado foi extremamente fortalecida. O puro seria o suposto território de teóricos; o aplicado, por sua vez, seria o domínio daqueles que fazem, dos mais práticos: dos que assim se consideram - livres da abstração teórica. Mesmo que a fronteira entre o conhecimento e sua aplicação possa ser interpretada como falaciosa, ela se fortalece como uma fantasia que separa o pensamento do texto e o texto da ação. Quais as repercussões dessa fronteira no saber geográfico e na produção do conhecimento sócio-espacial?

O objetivo desse estudo é, de forma preliminar, refletir sobre algumas fronteiras construídas ao longo da construção do pensamento moderno. São focalizados, aqui, os limites que freqüentemente colocam-se entre a produção do conhecimento e a sua aplicação. Em outros termos, focaliza-se a natureza dos limites postos entre o diagnóstico e a terapêutica, entre o conhecimento produzido e os movimentos referentes ao planejamento urbano-regional.

Os limites entre a produção do conhecimento e a ação têm origens nas referências estabelecidas pela modernidade: o ideal de "sujeito neutro". À neutralidade da ciência corresponde uma postura política do sujeito - objetividade - diante do objeto que procura conhecer. Tal relação implica na construção de uma outra importante posição política: a isenção do sujeito diante do "mundo conhecido". Surge, dessa confrontação, a ilusão de um conhecimento dissociado de sua aplicação.

A fronteira entre o puro e o aplicado, no âmbito da ciência moderna, assume formatos especiais e aparta o conhecimento produzido de sua aplicação: de um lado o conhecimento sobre o "mundo", de outro o planejamento do "mundo". A fronteira também repercute na geografia. Amplia a situação de crise. Potencializa a incapacidade crítica, presente em todos os setores do conhecimento aplicado.

A aplicação do conhecimento metamorfoseou-se em técnica, supostamente livre do saber que lhe deu origem. Por analogia, a aplicação do conhecimento transformase em planejamento, livre e que dispensa o saber. Técnica pura: como se não originasse de um saber reflexivo. Técnica pura: a negação do saber. Em outros termos, a técnica - também compreendida como ciência aplicada - adquire na sociedade uma imagem de independência do saber que a concebeu. Cria-se a expectativa de ruptura concreta entre ciência pura e ciência aplicada. Mas, desde sempre, a ciência é concebida tendo como referência a sua aplicação. A negação do saber: negação do vínculo com a sua aplicação. É assim que entre conhecer e intervir desenvolve-se uma fronteira, senão intransponível pelo menos perceptível nos discursos tidos como oficiais. Compartimentos estanques instituídos pela modernidade: diagnóstico e prognóstico.

\section{PLANEJAMENTO: REFLEXÕES INTRODUTÓRIAS ACERCA DE PRÁTICAS TRADICIONAIS}

A reflexão procura focalizar o conceito de planejamento. Toma o conceito de planejamento como equivalente ao de conhecimento aplicado ou ao de ciência aplicada. Planejamento é palavra que, nas últimas décadas, vem sendo utilizada para explicitar uma intenção de racionalizar operações, da maneira mais 
objetiva, em todos os setores da vida social moderna. A palavra já se desgasta, talvez pelo uso indiscriminado e, especialmente, pelas concepções equivocadas que contribuíram para a construção de inúmeros fracassos de natureza diversa. O conceito já se deteriora. Desde os anos setenta são intensificadas as práticas de planejamento, originárias do pós-guerra. Todas são identificadas com a intenção da modernização das instituições e com a expectativa de modernização da vida social. A idéia de modernizar está associada, freqüentemente, à perspectiva de progresso. Portanto, independente da situação, das "realidades", assim como das temáticas, planeja-se para modernizar: para crescer, para desenvolver. E, do mesmo modo, no mesmo nível de intenções, planeja-se para que tais objetivos possam ser alcançados mais rapidamente ${ }^{1}$.

$\mathrm{Na}$ maior parte das situações, contudo, modernização organizacional e modernização social adquiriram, historicamente, características de modernização conservadora. Planejar pode significar burocratizar. A burocracia pode ser entendida, também, como um sistema organizacional que viabiliza o fluxo de informações. A burocracia viabiliza o funcionamento institucional. Contudo, levada aos limites extremos, a burocracia, na maioria das situações, assume o papel de entrave à fluência de informações, de operações e do andamento dos processos necessários ao funcionamento dos sistemas.

Planejar pode significar a criação de normas, de estilos e de comportamentos padronizados e indesejáveis. Planejar pode implicar na produção de limites à criatividade. Planejar pode, ainda, simplesmente significar a elaboração de planos: para que sejam ignorados; para atender demandas políticas; para legitimar posturas políticas, democráticas, mas também demagógicas ou populistas. Estas últimas, com freqüência, são resultado e características de um planejamento clássico, conservador, tradicional, construído pela história. Entretanto, planejamento pode estimular resultados opostos aos descritos. Podem, já na metodologia, ser concebidos para se desdobrar em práticas contrárias às descritas.
O que são planos tradicionais? De um modo geral podem ser identificados, desde a sua metodologia, pela característica compartimentada e fragmentada. O diagnóstico, conhecimento da "realidade" - objeto de tratamento -, é o primeiro grande compartimento a ser projetado $^{2}$. De um modo geral, os diagnósticos são peças que, no conjunto acabado dos planos, assumem um formato que os tornam contraditoriamente independentes. E, além disso, em muitas situações, os diagnósticos não cumprem o papel que lhes cabe: encaminhar soluções para os problemas constatados; atuar como ganchos, como um elo de ligação entre a "realidade" e a "intervenção na realidade". Assim, transformam-se em peças soltas, desconectadas, facilmente descartadas. Parecem dispensáveis, nos planejamentos tradicionais. Eles assumem o formato rígido da ciência moderna: pretendem sugerir uma impessoalidade e uma imparcialidade inatingíveis. Escapam da finalidade que, no discurso, lhes é imposta: diagnosticar para transformar, conhecer para transformar.

Os planos tradicionais, além de serem compreendidos e trabalhados a partir da construção de peças estanques - como diagnósticos e prognósticos -, também são elaborados "à distância" do objeto de intervenção. Esta distância é efetivada a partir de dois atos. O primeiro deles é fruto de uma atitude explicitamente metodológica: o planejador coloca-se à distância do "objeto" de conhecimento e de transformação, não importa qual a sua natureza. Uma falsa distância. Imparcialidade e objetividade: características e atributos arraigados ao pensamento moderno. O segundo deles está associado ao primeiro e é construído a partir de uma atitude também metodológica: planeja-se "de cima para baixo". Supõese a existência de uma "elite pensante", pronta para conceber o mundo - conhecer e transformar -, independentemente dos que estão "dispensados" do trabalho de concepção. Assim, planeja-se à revelia do "objeto", que pode ser uma comunidade, um bairro, uma cidade, uma região. Os riscos são evidentes: os planos perdem legitimidade, não sendo construída a relação

1 - Um dos estudos de AB' SÁBER, antes de abordar a contribuição da geografia em processos de intervenção, apresenta alguns significados de planejamento: "Planejar significa elaborar planos de melhoria. Significa encontrar diretrizes para corrigir os espaços mal organizados e improdutivos. Significa encontrar meios e propiciar condições para interferir nos setores menos favoráveis de uma estrutura ou de uma conjuntura. Significa criar recursos econômicos suficientes para melhorar as condições de vida das coletividades humanas de uma região ou de um país. Significa aproveitar e adaptar exemplos e padrões adequados, venham eles de onde vierem. Significa encontrar fórmulas para um desenvolvimento regional harmônico. Significa modernizar e estender o desenvolvimento por vastos espaços. Significa, enfim, afastar os fatores de inércia cultural e econômica, e realizar um progresso globalizado, em curto espaço de tempo, e à custa do melhor dos bom-sensos possíveis" (AB' SÁBER, 1969: 11-12). CERON \& GERARDI, já no início dos anos oitenta, também focalizando a geografia, apresentam uma contribuição à caracterização do planejamento. Conforme os autores, "A planificação pode ser caracterizada de diversas maneiras e todas apresentam indubitavelmente componentes comuns. Aqui, a planificação será entendida como sendo um corpo de conhecimentos e práticas destinadas a orientar e permitir a tomada de decisões sociais de forma racional e ótima, para melhor organizar e mobilizar recursos visando ao bem-estar econômico e social em escala local, regional ou nacional" (CERON \& GERARDI, 1981: 108).

2 - Os planejamentos convencionais, aqui também denominados clássicos, adotam uma terminologia similar ou análoga à terminologia médica. A "realidade", não importa qual - se econômica, se política, se regional ou urbana etc. -, é "tratada" como se apresentasse um quadro patológico. Portanto, pressupõe-se que a "realidade" esteja "doente", desequilibrada. O mundo é, assim, abordado como "paciente". Os diagnósticos objetivam analisar os sintomas do quadro, que são menos ou mais explícitos, para posteriormente averiguar (análise) as causas (processos) que contribuem para o estabelecimento de quadros "indesejáveis". 
de identidade entre as estratégias de intervenção e os interessados nas mudanças.

Como decorrência da postura metodológica em questão, os planos correm maiores riscos de serem abandonados, adulterados e muitas vezes assumindo o formato de intervenções prejudiciais. Como crítica às posturas clássicas da modernidade - referentes à produção do conhecimento e à sua aplicação -, adquire amplitude a observação: planos deveriam serfeitos com e não para. Os planos deveriam estimular a democracia, desde a sua concepção, com toda a complexidade incorporada à alternativa.

Mas não é apenas isso. Planos tradicionais são a resposta imediata à concepção tradicional de ciência. Ciência moderna: “... considerada o lugar nãoideológico” (Resende, 1982: 28). A observação, conforme anota a autora, esconde a situação de que a produção do saber esteja “... ligada às necessidades concretas de sua aplicação ...” (Resende, 1982: 28). De acordo com a suposição de que o conhecimento seja neutro, objetivo e a própria manifestação da racionalidade, planos são elaborados para a reconstrução de uma "ordem rompida"3. A crise, entendida como ruptura da ordem, “... como um movimento da irracionalidade que invade a racionalidade ..." (Resende, 1982: 30), estaria sempre demandando a "restauração da racionalidade". O planejamento: a racionalidade restauradora da ordem e da crise ${ }^{4}$.

\section{A PESQUISA E O ENSINO COMO JUSTIFICATIVAS PARA INSERÇÃO DE LIMITES}

No mundo moderno os problemas sócio-ambientais são reproduzidos e ampliados em grandes proporções: crise urbana, crise social, crise ambiental. Cientistas e governantes devem se preocupar com a solução desses problemas e criar condições para impedir que outros se introduzam: observações de Guidugli (1980: 1). Tais anotações se ajuntam à outras equivalentes, em uma vasta produção literária específica, sublinhando uma crescente preocupação com a emergência dos problemas sociais e ambientais. O conhecimento dos problemas deveria estimular a acumulação de esforços para viabilizar a sua solução. Ciência e política. O geógrafo apresenta o caráter político do conhecimento geográfico:

"A preocupação com o uso de todo o conhecimento gerado deve ser uma constante na reflexão daqueles que necessitam oferecer respostas válidas aos vários problemas que a sociedade enfrenta. Assim, a geografia e os geógrafos como cientistas devem tornar-se cada vez mais preocupados com tais questões" (Guidugli, 1980: 1) $)^{5}$.

O texto do autor estimula reflexões e reforça dúvidas e fronteiras. "Os geógrafos como cientistas": qual o significado da expressão? O texto parece, em primeiro lugar, sublinhar uma personagem: "o geógrafo cientista", distinto do "geógrafo não-cientista". Outra interpretação derivada: haveria uma geografia científica, distinta de uma geografia não-científica. A geografia não-científica seria aquela "voltada" para o ensino? O que dizer dos professores em sala de aula? Haveria um ensino "não-científico" da geografia? O que significa ser científico? E, mais adiante, como haver profissionais do ensino distantes da pesquisa? O que dizer de uma química, uma física ou de uma economia não-científica? Guidugli encaminha um conjunto de indagações:

também o dever de envolver-se, de maneira prática, com um variado elenco de problemas espaciais, contribuindo assim para a sociedade humana? Qual é a amplitude do conjunto de oportunidades para a aplicação da pesquisa geográfica? E, em caráter mais específico, como estabelecer uma relação proveitosa entre geógrafos face ao planejamento e aos planejadores, de tal maneira que se possa desenvolver uma geografia aplicada ou uma aplicação prática de suas pesquisas?" (Guidugli, 1980: 1). ${ }^{6}$

Todas as questões levantadas pelo autor estão relacionadas à "utilidade" da geografia. Nas problematizações do autor podem ser identificados alguns traços da ruptura: entre o puro e o aplicado. Fronteiras no cerne de uma crise: da ciência, da

\footnotetext{
3 - A busca da ordem, especialmente traçada como projeto da modernidade positivista em expansão, termina por lapidar contornos conceituais do que sempre se entendeu por equilíbrio. O desequilíbrio seria uma situação patológica, demandando uma intervenção racional, técnica, especializada na ótica da economia. Políticas regionais seriam, portanto, equivalentes à adoção de estratégias de ampliação das fronteiras do progresso e da modernidade. O paradoxo do progresso, contudo, reside tanto na sua própria trajetória como nos resultados que constrói. A modernidade, que também na ciência se realiza na especialização, é reproduzida através da ampliação de fraturas no processo produtivo, da ampliação da própria produção e, especialmente em sociedades pouco democráticas, da própria extensão das desigualdades.

4 - "Dentro da área do planejamento urbano, a crise urbana é comumente invocada no sentido de se elaborar um plano ou efetuar um conjunto de ações que lhe dêem fim e restabeleçam a ordem. À irracionalidade do urbano é oposta a racionalidade dos planos de urbanismo, que nomeiam os pontos de desordem na tentativa de equacioná-los. Mais que isso, é empreendida uma tentativa de conhecer 'objetivamente' o espaço urbano, isto é, dominá-lo inteiramente pelas operações do intelecto, tentando dizer tudo o que o espaço urbano é ou deve ser" (Resende, 1982: 30).

5 - Em 1983, o autor volta a se manifestar sobre a importância da construção de uma disciplina também incumbida com a solução de problemas da sociedade: "O valor, a perspectiva de contribuição da geografia para a sociedade humana não podem continuar a ser medidos pela questão: o que fazemos? Mas sim pela: o quanto é bom e útil o que fazemos" (Guidugli, 1983: 207).

6 - "O geógrafo integrou-se como categoria profissional ligada a diversos órgãos de planificação existentes nos países desenvolvidos praticamente a partir da Segunda Guerra Mundial. Anteriormente, houve participação de profissionais em casos isolados, isto é, um ou outro ocuparam, notadamente, cátedras universitárias" (Gomes, 1984: 119).
} 
geografia. Primeira problematização: a geografia é "ciência predominantemente de ensino" ou deve, "de maneira prática", envolver-se com problemas espaciais? Questiona-se: o ensino não é uma atividade eminentemente prática? Através do ensino não se pode, também, contribuir para a transformação da sociedade? O ensino é colocado, aqui e em várias outras situações que discutem a natureza da geografia, como uma atividade distante da "realidade" social. A história do ensino da geografia - e de outras disciplinas - pode ter adquirido tais características: como a própria ciência adquiriu. Mas sempre foi um espaço potencial para a transformação social. Talvez a natureza "academicista" do ensino esteja, de fato, relacionada à natureza "academicista" da ciência, próprias da cultura moderna. Ensino, distante do "mundo concreto"; ciência pura, distante de sua aplicação.

Indícios de tais fronteiras podem ser observados nas duas últimas problematizações de Guidugli (1980:1), relacionadas à "aplicação da pesquisa geográfica", à "geografia aplicada" e à "aplicação prática" das pesquisas geográficas. O estudo de Guidugli ilustra a concepção de ciência - e de geografia - que distingue o puro do aplicado. Ele se submete à existência de uma ciência pura e de uma geografia pura, distantes de uma ciência aplicada e de uma geografia aplicada. Fronteiras inconsistentes e inexplicáveis. Entretanto, o limite entre o puro e o aplicado torna-se barreira concreta que justifica e impede uma renovação ética das práticas dos cientistas/planejadores. Talvez seja essa barreira que, de fato, construa problemas e motive preocupações como a de Guidugli (1980: 1), “... com o uso de todo o conhecimento ...". Barreiras que criam ilusões, falsas fronteiras, que separam a ciência de sua aplicação, de seu uso. Entretanto, sempre deve ser tomada a referência de que a ciência é, também, o uso que se faz dela.

\section{GEOGRAFIA E PLANEJAMENTO: FRONTEIRAS ENTRE CONHECIMENTO E TRANSFORMAÇÃO}

A geografia sempre se organizou como uma disciplina voltada para produzir informações de caráter sócio-espacial, apresentadas como básicas do planejamento sócio-espacial. Tais informações, recolhidas do ambiente físico-biológico e do meio sócio- econômico, sempre encontram o seu lugar na linguagem, no texto da disciplina e no trabalho cartográfico. $\mathrm{O}$ texto e o mapa.

O texto: basicamente descritivo ${ }^{7}$. Se o conhecimento é reduzido à descrição de imagens e de formas espaciais, o planejamento limita-se à intervenção no mundo das aparências. O planejamento, também, sempre corre riscos de desviar-se da essência dos problemas a serem trabalhados e se concentra, quando no máximo assim se realiza, nos resultados: formas e imagens perceptíveis, originárias também de um conjunto de relações invisíveis não abordado pelo processo de conhecimento. É certo que a tradição das imagens e do fisicismo não é monopolizada pela geografia. A imagem - e quase sempre só a imagem - tem a sua importância multiplicada com a reprodução da modernidade. $\mathrm{O}$ mundo é reduzido aos seus aspectos físicos e à sua dimensão perceptível ao olhar físico ${ }^{8}$. Nessas circunstâncias, as estratégias de planejamento não podem ser sempre interpretadas como portadoras de crítica e de história. Elas são o reflexo da forma como o conhecimento foi produzido. No âmbito das relações entre o processo de conhecer e o ato de transformar em verdade processos de um todo indivisível -, são consolidadas a fragmentação e a fragilização do saber útil à construção de uma realidade compatível com os ideais propostos por uma ciência de fato crítica e criativa.

O mapa: síntese visual representativa dos lugares. A produção da geografia, desde os primórdios do processo de sistematização do conhecimento geográfico, sempre esteve identificada com os inventários. Inventários locacionais. Uma produção compreendida como base do planejamento. Planejamento: urbano, rural, regional, ambiental. Não é incomum que profissionais da geografia percebam assim a sua disciplina: como fundamento. Não é também infreqüente que profissionais da geografia compreendam que o seu trabalho seja concluído com o mapa9. Após o texto descritivo, que muitas vezes assume a pretensão de analítico-explicativo, após o mapa-síntese, não há mais o que realizar. O inventário está concluído, o texto da geografia encerrado.

Desde a Geografia Clássica, a produção central da disciplina geográfica esteve referenciada pelas monografias regionais. A intitulada Escola Francesa de Geografia foi difundida através da produção das

\footnotetext{
7 -"A Geografia distingue-se como ciência essencialmente descritiva. Não seguramente que renuncie à explicação: o estudo das relações dos fenômenos, de seu encadeamento e de sua evolução, são também caminhos que levam a ela. Mas esse objeto mesmo a obriga, mais que em outra ciência a seguir minuciosamente o método descritivo" (LA BLACHE, 1982: 45). O texto do autor francês é publicado originalmente com o título "Des caractères distinctifs de la Géographie". In: Annales de Géographie, 22 (124): 289299, 1913.

8 - CORAGGIO motiva a reflexão sobre a necessidade e importância da emergência consistente de alternativas críticas, que promovam o desenvolvimento de fundamentos teóricos para: a compreensão da "... problemática territorial como uma questão social ..." (CORAGGIO, 1987: 70); a compreensão da crise urbana, por exemplo, em todos os seus múltiplos aspectos, como uma questão das coletividades urbanas e não como da cidade física. Estar-se-ia, como acrescenta o autor, “... evitando o fisicalismo e a coisificação características das concepções dominantes” (CORAGGIO, 1987: 70).

9 - É certo que os mapas são instrumentos de conhecimento. Mas, nessa passagem, o conceito de mapa é apresentado como sinônimo do conceito de "síntese geográfica": o mapa como síntese representativa do "mundo concreto".
} 
pesquisas de caráter regional. Inventários regionais que se confundiam com os clássicos diagnósticos regionais, fundamentos do planejamento regional. Não é, portanto, destituída de lógica - alicerçada por uma prática histórica -, a percepção de que o trabalho geográfico finaliza-se nos inventários ou nos diagnósticos. Portanto, estão sendo apresentados simultaneamente dois problemas, assim resumidos: 1) o texto geográfico conclui-se no diagnóstico sócio-espacial; 2) o diagnóstico - valendo a observação para todas as disciplinas científicas - é realizado de forma estanque, na desconsideração dos movimentos subseqüentes relacionados às estratégias de planejamento.

No que diz respeito à posição dos geógrafos, existe a consensualidade de que são fortíssimas as amarras que se estabelecem entre a sua disciplina e o planejamento $^{10}$. Entretanto, contraditoriamente, os próprios geógrafos não são explícitos no que se refere à sua posição como planejadores: colocam-se à disposição dos planificadores. Aproveita-se a observação de Bernardes, no final dos anos sessenta:

“A inestimável contribuição da Geografia para o planejamento decorre do fato de ser ela a ciência que procura, exatamente, aprender e interpretar a combinação de fatos em determinado ponto da superfície do Globo, e de como distintas combinações ocorrem caracterizando o espaço geográfico considerado. O método geográfico oferece uma abordagem regional ... no estudo de problemas de desenvolvimento sócio-econômico, de mobilização de recursos naturais e humanos e no arranjo das atividades humanas no espaço, o que representa uma base segura para os diversos especialistas de outras disciplinas e para os técnicos de planificação. Por isso mesmo o emprego da Geografia, e o concurso dos geógrafos, começou a se fazer espontaneamente na Grã-Bretanha, pioneira mundial no campo do planejamento territorial, quando as primeiras equipes começaram a reunir dados e a realizar estudos básicos para os planos regionais" (Bernardes, 1969: 2).

Melo reforça as observações de Bernardes, apresentando as aptidões da geografia para o tratamento de problemas regionais através da produção de informações necessárias ao planejamento:
"Trata-se, como se sabe, de um conhecimento de feição globalista, abrangendo os quadros naturais $e$ os quadros humanos interpretados ambos em função das relações de cada um de seus elementos para com todos os demais. Daí a aptidão da geografia regional em surpreender problemas regionais ... Maior será essa aptidão se orientar-se a pesquisa não apenas pelo interesse científico ... mas também ... pelo interesse de identificar e definir problemas e de indicar diretrizes para sua solução. Nesse caso, poder-se-á falar de um diagnóstico geográfico de determinada região tão legitimamente quanto de um diagnóstico econômico" (Melo, 1969: 8).

Melo enfatiza, explicitamente, a distância entre a produção e a utilização da informação: como se fossem compartimentos ou processos estanques. Sublinha os limites entre o conhecimento produzido, motivado pelo interesse científico, e a sua aplicação. Mas, afinal, o que motivaria a busca de informação científica sobre determinado problema senão a necessidade de encontra a sua solução? Saber desinteressado? E, quanto a geografia, conforme o autor, se equipararia à economia apenas no tocante à elaboração dos diagnósticos. $\mathrm{O}$ autor demarca a fronteira da disciplina e de seus profissionais: "Em uma palavra a contribuição geográfica é básica no diagnóstico e apenas complementar na terapêutica” (Melo, 1969: 8) ${ }^{11}$.

Melo considera a economia básica no diagnóstico e na terapêutica. Entretanto, especialistas das ciências econômicas freqüentemente desconsideram ou subdimensionam os processos sociais envolvidos no ato de crescer, trabalhando a dimensão regional, na maioria das situações, exclusivamente em sua base física. Desenvolvido, assim, passa a ser aquilo que cresceu e continua apresentando potencialidades para o crescimento e para a ampliação das fronteiras da modernidade. Tais idéias adquirem o mesmo significado quando se trata de refletir sobre a problemática urbana. O espaço, apesar da pretensa renovação dos discursos, tem sido trabalhado exclusivamente em sua base física. Nesse sentido, diante do fisicismo das interpretações, verifica-se uma naturalização ou uma biologização de processos que, efetivamente, são constituídos pela dinâmica social. O genuíno novo, que de fato representa

10 - Anotações de PAVIANI (1984) mostram que, de fato, as relações entre a geografia e o planejamento são importantes a ponto de influenciar não apenas a produção dos profissionais nas instituições, mas também a natureza e o volume das reflexões teóricometodológicas desenvolvidas pela disciplina: "A Geografia Urbana brasileira, ao longo dos últimos trinta anos, esteve mais preocupada com os problemas de polarização, de redes urbanas e Teoria do Lugar Central, que ocuparam mais páginas de artigos e livros sobre trabalhos empíricos. Uma das justificativas para a ênfase apontada reside no fato de que, durante o período, os geógrafos foram chamados a dar uma contribuição ao assim denominado 'planejamento urbano-regional', tanto a nível dos estados quanto das regiões e do País como um todo" (Paviani, 1984: 81).

11 - MELO observa que a economia, por sua vez, contribui nas duas fases: no diagnóstico e na terapêutica. Contudo, é bastante questionável a posição de destaque conferida à economia por MELO em relação às outras disciplinas. Para se fazer referência ao planejamento sócio-espacial, conforme observa GUIGOU, “A terra e o espaço são, para os economistas, objetos de análise a um só tempo desorientadores e dificilmente integráveis. No entanto, é indispensável levá-los em conta na análise econômica” (Guigou, 1986: 132). O autor apresenta a interpretação de que a terra e o espaço demandam uma abordagem multidisciplinar, sendo que “... os economistas não podem ignorar o papel que a terra representa na economia geral nem a dimensão espacial sem correrem o risco de propor teorias e políticas pouco realistas e, por isso mesmo, ineficazes" (Guigou, 1986: 132). 
transformações de relevância, deve ser entendido, através de uma nova ética a ser construída, como movimento na direção da superação do que sempre se chamou de moderno na ciência e no planejamento. Diante de novos valores, que peso afinal teria a discussão acerca dos obstáculos a um crescimento socialmente justo e propagado por todo o território? Diante de novos valores, introduzidos tanto na política quanto na ciência, a justiça social seria a própria meta e não um efeito colateral que jamais se realiza espontaneamente.

Se Melo considera a economia como básica no "diagnóstico e na terapêutica", enquanto Guigou (1986: 32) observa que o espaço é motivo de "desorientação" para os economistas, o que pensar sobre arquitetos e engenheiros envolvidos com o planejamento? A história do planejamento urbano confunde-se com a do urbanismo. Já nos momentos iniciais da história do planejamento - especialmente urbano -, é definido nas instituições o predomínio de técnicos com formação nas áreas de arquitetura e de engenharia. Entretanto, a arquitetura, a engenharia e o urbanismo tradicionais também não se prepararam para abordar a natureza social das questões territoriais, em todos os seus níveis, dimensões e em toda a sua complexidade. A priorização do mundo físico nas abordagens atesta a observação. Os geógrafos, mesmo com a convicção da qualidade de sua contribuição, permaneceram na retaguarda quando não reforçavam a posição da disciplina como exclusivamente básica no diagnóstico.

No final dos anos sessenta, as posições assumidas por AB'Sáber são registradas e algumas passagens de uma de suas contribuições são selecionadas para uma breve avaliação. Em primeiro lugar, o autor apresenta um grupo de vantagens a favor dos geógrafos envolvidos com as atividades de planejamento ${ }^{12}$. Contudo, o autor também associa o trabalho do geógrafo sobretudo às suas contribuições ao desenvolvimento dos estudos de diagnósticos: “Aos bons geógrafos destina-se um extenso setor de trabalhos prévios para o reconhecimento de situações...” (AB’Sáber, 1969: 18). Quanto aos outros profissionais, no entendimento do autor, que inclui sociólogos, economistas, arquitetos, urbanistas etc., “... ficará encomendada a etapa final dos estudos básicos destinados à discriminação de diretrizes e propostas” (AB'Sáber, 1969: 18). AB'Sáber, em uma observação que merece ser sublinhada, aponta para a existência de apenas "um tipo de planejamento”: “... o planejamento integrado, realizado pelo somatório dos esforços de muitos tipos de pesquisas e de pesquisadores" (AB'Sáber, 1969: 18). Porém, tal observação conduz a reflexão para além do somatório: o planejamento integrado é muito mais multiplicação, concretizada pela mobilidade dos saberes e pela interpenetração de conhecimentos e aplicações. Desde os anos sessenta acumulam-se observações que fornecem consistência ao apelo interdisciplinar e, segundo o autor, o planejamento é atividade que estimularia as universidades a introduzir “... uma linguagem comum de novas relações interdisciplinares ...” (AB'Sáber, 1969: 23). Por este aspecto a posição do autor é avançada em relação ao momento. Permanece a percepção de um saber desvinculado de sua aplicação, assim como a construção de linguagens específicas.

Já no início dos anos oitenta, Ceron \& Gerardi produzem um artigo que não tem a finalidade de discutir, teoricamente, os papéis dos geógrafos nos processos de planejamento ${ }^{13}$. Entretanto, mesmo sem a intenção explícita, os autores externalizam pontos de vista que interessam ao estudo: em momento algum sublinham a geografia de forma diferenciada (em relação às demais disciplinas) e não apresentam fronteiras separando o conhecimento produzido de sua aplicação:

"Não é esta a melhor oportunidade para descrever atitudes tomadas pelos geógrafos com respeito à planificação e, muito menos, prescrever os tipos de comportamentos que deverão ser tomados pelos profissionais desta disciplina. Mister se faz tão somente colocar os geógrafos no seio de uma comunidade científica, representantes de uma ciência já sistematizada e formalizada e que, por esse motivo, deverão estar habilitados para se sensibilizarem com os grandes anseios e as situações com as quais a humanidade se depara, saber problematizá-los e, juntamente com profissionais de outras ciências, oferecer sua contribuição para solução dos problemas identificados com o auxílio do arsenal de métodos e técnicas colocadas à sua disposição" (Ceron \& Gerardi, 1981: 108).

12 - Em princípio, a capacidade de diagnosticar de um geógrafo não é muito maior do que a de um médico de clínica geral. E, nesse sentido, nos eximimos de sublinhar as grandes virtudes e as limitações dos clínicos. A favor dos geógrafos que pretendem se engajar em tarefas de planejamento existe apenas um grupo de vantagens - entre muitas desvantagens - ou seja: 1) o geógrafo inicia seus estudos diretamente através de observações sistemáticas de campo; 2) a grande especialidade do geógrafo moderno é a técnica de observação da organização do espaço; 3) possuindo sensibilidade para compreender a tipologia dos espaços organizados por diferentes agrupamentos humanos, os geógrafos podem colaborar decisivamente para encontrar soluções e sugerir novos padrões de organização, em cooperação direta com os especialistas integrados nos ideais de planejamento; 4) para abreviar o estudo das situações o geógrafo tem a seu favor o auxílio dos métodos e das técnicas da Cartografia geográfica e da Fotointerpretação geográfica” (AB’Sáber, 1969: 17).

13 - Os autores que, no referido texto, estão preocupados com uma discussão específica sobre "bases geográficas para planejamento rural no Estado de São Paulo", enfatizam: "Não se cogita, nesta oportunidade, de desenvolver a questão relativa ao papel da Geografia no Planejamento. Como muitas outras ciências a Geografia apenas inicia os seus primeiros passos em direção do planejamento, como corpo de conhecimentos científicos, interdisciplinares, sistematizados, capazes de conferir certa consciência da ação profissionalizante a uma comunidade de interessados" (CERON \& GERARDI, 1981: 108). 
Ainda nos anos oitenta, experimentando uma pequena expansão do mercado profissional para o desempenho de suas atividades, os geógrafos apoiamse em argumentos supostamente incontestáveis para questionar o modesto aproveitamento de sua contribuição: a sua capacidade de síntese ou a sua privilegiada visão de conjunto $^{14}$. É o que pensa Gomes (1984). O autor lamenta o fato de que as municipalidades, apesar de trabalharem "... sobre uma realidade representativa em bases geográficas ..." (Gomes, 1984: 121), não aproveitam o trabalho do geógrafo $^{15}$. As anotações do geógrafo são também importantes porque, sob vários aspectos, ratificam a opinião quase consensual a respeito dos papéis da geografia no planejamento: "Os inquéritos geográficos são múltiplos no que tange ao planejamento em micro ou em macro-escala ...” (Gomes, 1984: 125). O autor sublinha novamente porque a presença da geografia “... não pode e não deve ser ignorada, preterida pelo corpo do planejamento integral" (Gomes, 1984: 125): "Como sabemos, as investigações de conjunto dão melhor estruturação e significado científico aos planos concebidos" (Gomes, 1984: 125). Em princípio não se está discordando do autor. O que se deseja é, a partir de contribuições diversificadas, discutir o formato de ciência compartimentada que ele também apresenta: de um lado o "diagnóstico", de outro a "aplicação" do conhecimento $^{16}$. O referido geógrafo também não se desvencilha da regra. Em primeiro lugar, faz menção ao inquérito geográfico ressaltando a sua qualidade por apresentar uma visão de conjunto. Mais adiante, substitui a palavra inquérito por investigação, ainda reforçando o caráter enriquecedor da geografia nas abordagens interdisciplinares: “... ela interpreta ligações ... estruturando em última análise, uma visão do todo (sintese)" (Gomes, 1984: 125). O papel da geografia estaria confinado, segundo a maioria das interpretações, ao diagnóstico, às investigações, aos inventários, aos estudos de base necessários ao planejamento. O futuro estaria encaminhado aos especialistas do planejamento, como observa
Philliponneau, também aproveitado por Gomes:

"Delimitada a área de estudo regional, o geógrafo procura reunir o máximo de documentação e passa, através dessa documentação, a analisar os caracteres essenciais da região, as grandes linhas de sua evolução, a precisar o estado atual da situação demográfica e os diversos ramos da atividade econômica e, sobretudo, assegurar a síntese das relações particulares elaboradas por diferentes especialistas" (Philliponneau, 1964, apud Gomes, 1984: 126). ${ }^{17}$

Mais adiante, já nos anos noventa, apesar da progressiva ampliação de oportunidades para o trabalho do geógrafo, as posições com respeito à participação dos profissionais não parece ter se modificado substancialmente. Veja-se com Veloso:

“... o geógrafo estará habilitado a exercer funções diversificadas ao longo do processo de estudo, planejamento e implementação de um SGA ... Especialmente na fase de diagnóstico, muitas atividades poderão ser delegadas ao geógrafo principalmente considerando-se que o diagnóstico constitui basicamente uma avaliação de impacto ambiental da empresa ao longo de todo o tempo de sua atuação" (Veloso, 1996: 49).

Para a ciência "convencional", o processo de conhecimento deve isentar-se da intenção de transformar. A transformação ou a intervenção na "realidade", segundo os paradigmas clássicos da modernidade, é uma atitude ideológica. Como poderia não ser? E, antes disso, como conceber o processo de conhecimento de forma diferente? Em outros termos, como não compreender o conhecimento como conhecimento para transformação? Foi assim, desde o início dos tempos modernos da ciência. A produção do conhecimento - produção da informação, organização da informação - sempre esteve conectada aos diversos projetos de transformação do mundo dos quais, inclusive, a geografia sempre esteve presente em maior ou menor escala: exploração, conquista, incorporação. Não poderia haver distinção entre um

14 -"Compreendida a Geografia de hoje como uma ciência estruturada em princípios, métodos e propósitos científicos cujo objeto fundamental se acha localizado no corpo das combinações espaciais e cuja função básica consiste em revelar em forma de síntese - esta compreendida como visão de conjunto - o máximo de relações espaciais (espaço produtivo/social) estruturadas no todo que se pesquisa, resta-nos estabelecer algumas reflexões necessárias. O que se busca são relações de causalidades, de conexidades, afinidades, atividades estas integrantes dos fenômenos naturais, bióticos e humanos que compõem o cenário da Terra como um organismo vivo que envelhece e se renova continuamente" (GOMES, 1984: 120).

15 - A realidade de que trata o autor é estabelecida pelas “... condições naturais e sociais do espaço urbano, os fatores demogeográficos contidos no habitat concentrado e disperso, a produção material e a tipologia funcional, o sítio urbano e as etapas do crescimento espacial, a posição da cidade e suas relações com o campo e vice-versa, a rede urbana e sua integração na malha viária etc. ..." (GOMES, 1984: 121).

16 - No início dos anos oitenta, em rápida conclusão de um capítulo de seu livro, CLARK (1985: 264) não diferencia e tampouco compartimenta o trabalho dos geógrafos no planejamento urbano: “Embora não possam 'resolver' os problemas da cidade, os geógrafos urbanos podem contribuir substancial e construtivamente para o debate urbano. Eles podem identificar as relações básicas, monitorar os processos em evolução, identificar as opções de planejamento e avaliar os prováveis resultados. Junto a outros especialistas da cidade, eles podem ajudar a assegurar que as políticas que forem selecionadas para modelar a cidade do futuro, representem uma escolha deliberada, considerada e informada." O referido texto é extraído da tradução, para o português, da obra de CLARK. Urban Geography: an introductory guide. Londres: Croom Helm Ltd., 1982.

17 - O texto aproveitado por GOMES, H. é extraído de PHILLIPONNEAU. Geografia e Ação. Lisboa: Edições Cosmos, 1964. 
saber puro de um saber aplicado. Não poderia haver uma geografia pura, comprometida exclusivamente com a fotografia. Ela jamais poderia isentar-se do futuro.

\section{A CONTESTAÇÃO DOS LIMITES DO EQUIVOCO}

Produzir a informação, utilizar a informação: se há uma fronteira entre os dois processos não há como não pensar em crise e contradição. Admitir uma brecha entre uma ciência pura e uma ciência aplicada é ampliar a rede de fronteiras: entre o teórico/acadêmico e o prático, o conhecimento e sua aplicação, a sala de aula e os gabinetes de pesquisa ${ }^{18}$. Fronteiras ideológicas e corporativistas que, também, justificam o inexplicável: a neutralidade de quem produz a informação diante daqueles que a consomem. "Aplicar ciência” é produzir informação e acompanhar a sua utilização, o seu consumo. E sublinha-se: "Acompanhar não é assistir: é interferir, mudar” (Ferreira, 1988: 61). Produzir conhecimento sem se envolver com o objeto de conhecimento; planejar o mundo concreto sem se envolver com o objeto de planejamento: atitudes que refletem paradigmas tradicionais da ciência moderna, questionada. Veja-se com Matus (1987):

"Toda esta revolución en la teoría de la planificación puede explicarse a partir del cuestionamiento de un supuesto básico en que descansa todo el edificio teórico de la planificación tradicional. Ese supuesto es el siguiente: el actor que planifica está fuera o sobre la realidad planificada y en consecuencia no coexiste en esa realidad con otros actores que también planifican” (Matus, 1987: 55).

Para que se valorize as observações de Guidugli, e se desejar-se de fato avaliar "o uso que se faz do conhecimento", dever-se-ia tomar como premissa a ciência como um processo integrado, não compartimentado. $\mathrm{O}$ cientista e o planejador são a mesma personagem. E, já no método e nas metodologias, o diagnóstico e os planos, o pensamento e a ação, deveriam ser avaliados como atitudes e momentos superpostos. Não se poderia conceber uma ciência produtora de informações distante de outra aplicadora, isentando personagens que deveriam se responsabilizar pelas suas ações. Além disso, nas diversas marcações de tempo do processo, não se poderia conceber atitudes compartimentadas: produzir informações (tempo 1); aplicar informações (tempo 2). Afinal, não se planeja o futuro tendo o mesmo como referência única:

"Na realidade, utilizando uma frase que escandaliza muitos, porém que é muito efetiva e exata para expressar a idéia, a planificação se refere ao presente. Creio que, para além da efetividade desta frase, ela expressa estritamente a verdade. Tudo o que fazemos para explorar o futuro pelo prazo de um ano, cinco anos ou quinze anos não tem importância nenhuma se as mesmas explorações não orientam a ação de hoje. Tudo o que faz a planificação para simular o futuro é muito útil, porém é apenas um produto intermediário cujo produto final é a decisão que devo tomar hoje” (Matus, 1989: 111) $)^{19}$.

Se o planejamento pode ser compreendido como um processo que, explorando o futuro, organiza e orienta as ações do presente, ainda concorda-se com Matus (1989: 111): "Se a planificação deve ser útil como cálculo que precede e preside a ação no dia-adia, tal cálculo não deixa tempo para escrever 18 volumes." Planejar, portanto, é processo que passa a ser concebido a partir de atitudes muitas vezes superpostas no tempo: conhecer e agir. Tais observações, questionando as fronteiras entre o puro e o aplicado, entre o conhecimento produzido e sua aplicação, entre diagnóstico e prognóstico, ainda fornecem subsídios para uma discussão acerca das preocupações de Guidugli (1980) com respeito ao uso do conhecimento. As referências trazidas por Matus podem ser utilizadas como intermediárias para a construção de um argumento articulado. Veja-se como Matus (1989) oferece caminhos para uma reflexão sobre

18 - Interpretações pertinentes sobre a questão podem ser recolhidas de BRONOWSKI, que destitui aingenuidade e opuro da observação científica. A ciência é sua aplicação. O conhecimento é produzido para transformar o mundo. Veja-se com BRONOWSKI: "Ao usar a palavra 'observação' tenho consciência de ter traçado uma imagem demasiado passiva da ciência. Podemos ainda sucumbir à tentação de pensar que o mundo vai seguindo o seu curso poderoso e, de passagem, impressionando periodicamente o cientista com um vislumbre de seu imperturbável movimento. Isso seria um grave equívoco. Na verdade, perpetuaria o hiato entre o mundo e o experimentador que tenho tentado obviar. A ciência não é racional; é também empírica. Ciência é experiência, ou seja, atividade ordenada e raciocinada. A essência da experiência e de toda a ciência é ser ativa. Não contempla o mundo, mas o conduz ... Isto, sem dúvida, não é peculiar à ciência. Vida é ação e a vida humana é ação pensada. Se isso é suficientemente evidente quanto à vida, é preciso todavia sublinhar-se quanto à ciência, porque a ciência é uma atividade característica da vida humana. É característico da vida humana escolher a cada passo entre diversas alternativas que julgamos ter pela frente: os homens podem visualizar essas alternativas e os animais provavelmente não; mas, em ambos, ação significa escolha - quer se suponha que a escolha é livre, quer circunscrita. Em ambos os casos a ação está dirigida para o futuro. Os homens têm consciência dessa direção e escolhem uma ação de preferência a outra na esperança consciente de que os conduzirá a uma espécie de futuro preferível a outro" (BRONOWSKI, 1977: 90).

19 - "O problema dos prazos na planificação tem, então, sua origem teórica na impossibilidade de se tomar uma decisão racional hoje, sem explorar o futuro. Esta exploração do futuro é imprescindível, porém não é o coração do plano. O coração do plano é a tentativa de governar um processo, e um processo só se governa por meio da ação. Conseqüentemente, a planificação se refere ao presente e isto lhe dá um grande sentido prático, liberando-a do sentido livresco que tem até agora" (MATUS, 1989: 111). 
as relações entre o diagnóstico e a ação e, especialmente, sobre a postura do cientista / planejador:

"O diagnóstico tem sido difundido como a busca de uma verdade, una, única e científica. É interessante que a categoria diagnóstico foi criada pelos médicos, para propósitos específicos da saúde e foi extraída da medicina para a planificação. Em uma situação existem distintos atores sociais, que possuem distintos planos, perseguem diferentes objetivos e estão inseridos de distintas formas na realidade. Não é possível colocar-se de acordo com esses atores sociais, como em uma junta médica. Não existe uma 'verdade' única para eles. É como se alguns médicos tivessem interesse em que o doente morresse e outros em que vivesse. Porém, no sistema político-social, o que é vida ou é morte é uma questão de pontos de vista; não pode ser resolvido nas ciências” (Matus, 1989: 114).

Portanto, a explicação da realidade não poderia estar fundamentada exclusivamente na percepção do "sujeito-ciência” ou de um "sujeito-ciência”: “...não posso atribuir-lhe minha explicação e minha racionalidade” (Matus, 1989: 114). O argumento é base para a compreensão das fronteiras entre o puro e o aplicado e da própria crise da ciência:

"Não interessa, neste momento, se acredito que sua explicação é errada, é extremista, é direitista ou é ineficaz. Não interessam os qualificativos que se possa imputar-lhe. O que interessa é que sua explicação é a que o move a ter um plano distinto do meu, e o leva à ação que me obstaculiza ... Minha obrigação ... é entender sua explicação e incluí-la em minha explicação da realidade. A explicação do 'outro' é parte da realidade que devo explicar ...” (Matus, 1989: 114).

O uso do conhecimento, segundo a concepção apresentada, passa a ser compreendido como $a$ produção do conhecimento. Mais do que isso, adquire o formato de ampliação das fronteiras da utilização do saber. O eu passa a ser o outro também e, além disso, ultrapassa as fronteiras da primeira pessoa: a pessoa da ciência. Admitindo-se uma geografia aplicada não se pode concebê-la como atitude prática e isolada. Ao se refletir sobre as relações entre a geografia e o planejamento, não se pode conceber um conhecimento geográfico produzido à distância de sua aplicação. E, além disso, a construção da personagem geógrafo/planejador implica no desenvolvimento e estreitamento de contatos entre esse profissional, os outros e o "mundo concreto". Somente assim tem-se algum controle ético da produção/utilização do conhecimento.

\section{TENDÊNCIAS CONTEMPORÂNEAS: SINAIS DE APROXIMAÇÕES}

A aplicação do conhecimento científico, regulada por novos valores éticos, é intitulada por Santos (1989) como pós-moderna. A "aplicação edificante", como observa o autor, submete-se a novos valores e especialmente a valores éticos. Algumas de suas anotações evidenciam o caráter eminentemente ético que preside a aplicação do conhecimento: “... quem aplica está existencial, ética e socialmente comprometido com o impacto da aplicação" (Santos, 1989: 158). Para tanto, é necessário ao cientista balizar a aplicação do conhecimento referenciando-se, também, no objeto de intervenção: "O cientista deve, pois, envolver-se na luta pelo equilíbrio de poder nos vários contextos de aplicação e, para isso, terá de tomar o partido daqueles que têm menos poder" (Santos, 1989: 159). A proposta de Santos não é distante das observações de Coraggio, para quem a transição para uma nova sociedade tem início antes da situação de mudanças sócio-políticas: deve “... ser realizada na própria prática do planejamento com todas as contradições que ela é sujeita" (Coraggio, 1987: 65) ${ }^{20}$. O texto de Matus também reforça o argumento:

"A planificação não é monopólio nosso. Nosso plano enfrenta oponentes que também planificam. A idéia central ... consiste em considerar que, além de nós, há outros atores na realidade que também planificam com objetivos distintos dos nossos. Não temos o monopólio da capacidade para planificar como supõe a teoria tradicional, onde o Estado é o único ator que planeja, não reconhecendo a existência de oponentes" (MATUS, 1989: 119) ${ }^{21}$.

As observações de MATUS são reforçadas por Castells \& Borja (1996) que, ao abordar a crise das grandes cidades, sugerem propostas que envolvem os

20 - As reflexões de CORAGGIO deveriam ser tomadas como referência pelos cientistas planejadores: "A consideração das relações de poder não é uma imposição ideológica e sim uma necessidade óbvia de um planejamento eficaz. Quando se trata de programas que declaram como objetivo favorecer setores populares em contraposição a interesses de grupos minoritários, geralmente poderosos, o planejador consciente não deveria passar por alto pela necessidade de organização dos primeiros como força social, para sustentar o programa e resistir aos embates a que será submetido. A viabilidade política de um projeto não deveria ser um dado e sim objeto de construção, da mesma maneira que o é a obra física do projeto" (CORAGGIO, 1987: 77).

21 - " planificação pratica-se, pois, no contexto de um conflito de planos. Para os planificadores normativos tradicionais, isto é incompreensível, porque raciocinam perguntando-se: que outro ator é capaz de realizar um plano de desenvolvimento alternativo ...? Confundem a planificação com o plano normativo! Porém, se entendermos a planificação como o cálculo que precede e preside a ação, compreenderemos facilmente que ... todos os atores sociais têm objetivos, todos os atores fazem explorações sobre o futuro, $e$ todos os atores sociais, de alguma forma, articulam sua ação imediata em termos deste cálculo que precede e preside a ação e ofazem sem necessidade de escrever um livro. Contudo, o planificador tradicional continua pensando que se a planificação fosse imperativa tudo estaria resolvido. Supõem, conseqüentemente, que o ator que planifica tem poder absoluto e esse ator é o Estado. Se o plano pudesse ser uma lei da República estariam felizes e a planificação 'indicativa' teria solucionado problemas” (MATUS, 1989: 120). 
setores públicos e privados da sociedade ${ }^{22}$. Tais propostas, materializadas em "planos estratégicos" de desenvolvimento sócio-econômico de caráter urbano, seriam fundamentados e caracterizados por pontos básicos: “... ampla participação cívica, a descentralização dos governos locais, o andamento de grandes projetos urbanos de iniciativa pública elou privada, a cooperação entre ambos os setores ..." (Castellis \& Borja, 1996: 154). Percebe-se que a concepção de planejamento sugerida pelos autores já transcende os limites do Estado: o Estado planejador ${ }^{23}$. Não se faz, com isso, uma apologia do "Estado ausente". Passagens do estudo de Castellis \& Borja definem a importância dos setores públicos na promoção da aproximação com os setores privados e com as populações. Os autores referem-se, na oportunidade, às cidades latino-americanas:

"Podemos, na atualidade, falar de uma reação das cidades da América Latina? Sem dúvida alguma. Em primeiro lugar, a democratização e a descentralização dos Estados reforçaram e deram uma maior legitimidade aos governos locais ... Em segundo lugar, a abertura econômica, fator provocador de medos e gerador de oportunidades, mobilizou os agentes econômicos, que se conscientizaram da necessidade de contar com uma cidade competitiva, ... que assegurasse garantias mínimas de qualidade de vida e segurança pública. Esta conscientização levou-os a estabelecer objetivos e ações de caráter coletivo e compatíveis com o governo local ... Um terceiro ponto nos leva aos atores públicos e privados dominantes, que começaram a entender quão pouco viável é uma cidade que exclui ou marginaliza uma parte importante de sua população ... Em quarto lugar ... criam-se condições para a existência de amplos espaços de debate público com setores políticos, intelectuais e profissionais críticos e com as organizações sociais populares" (Castellis \& Borja, 1996: 157).

A avaliação dos autores não é incorreta, levando-se em consideração as importantes mudanças ocorridas na vida das cidades e no nível de discussão sobre seus problemas. Também não há como negar o otimismo contido na leitura apresentada. Entretanto, a interpretação de Castellis \& Borja é extremamente útil para que sejam rediscutidos, mais concreta e constantemente, a natureza dos papéis do Estado no planejamento sócio-espacial. E, ao fazê-lo, também discute-se a natureza das iniciativas dos planejadores incluindo os geógrafos - que Castellis \& Borja (1996: 157) parecem denominar de "profissionais críticos" 24. Os autores ainda recuperam o conceito de democracia, em sua dimensão sócio-espacial: "O princípio legitimador da autonomia é o da proximidade ..." (Castellis \& Borja, 1996: 158). Os autores referem-se à proximidade que maximiza contatos e relações imediatas envolvendo estruturas administrativas, território e populações. Os autores ressaltam a importância do Estado e, sobretudo, dos governos locais, na promoção da participação das coletividades - nas escolas do bairro, da cidade, da região - na gestão de programas de interesse público. Os autores investem, portanto, na discussão sobre as responsabilidades do Estado e dos governos locais na construção da democracia. Ratifica-se: “... o princípio da proximidade é um elemento essencial da legitimação democrática" (Castellis \& Borja, 1996: 161). Planejar, portanto, é construir as condições para a participação coletiva; é democratizar a informação para que o conhecimento e o seu uso possam ser questionados e até mesmo aperfeiçoados.

Questionar o uso do conhecimento é refletir também sobre os limites colocados entre ciência pura e ciência aplicada, entre produção do saber e planejamento. $\mathrm{O}$ planejamento não se explica por si só. A ciência não se explica por si mesma. O planejamento não é monopólio de planejadores. A geografia aplicada não é monopólio de aplicadores do saber geográfico. O saber não é monopólio. E, além disso, outros atores, muitas vezes "não-científicos", devem ser incorporados pela produção/aplicação do saber.

Tais anotações encontram o seu respaldo no "mundo empírico", na própria crise da concepção tecnocrática

\footnotetext{
22- ".. a consolidação dos processos democráticos internos e a crescente abertura externa multiplicaram as demandas sociais e acentuaram a sensação de crise funcional nas grandes cidades. A intensidade e a visibilidade dos problemas urbanos (congestionamentos, insegurança pública, contaminação do ar e da água, déficit habitacional e de serviços básicos) convergiram na sensação de crise" (CASTELLS \& BORJA, 1996: 154).

23 - Tal concepção é bastante distinta de trabalhos anteriores de CASTELLS, ao sugerir a cooperação entre o público e o privado como fundamento das iniciativas de planejamento.

24 - A valorização do tecnicismo e da concepção cartesiana no planejamento não são os únicos obstáculos para a construção de interpretações mais críticas pelo "cientista/planejador". Um problema que também afeta a perspectiva crítica do sujeito é a visão fragmentada que o mesmo pode estabelecer dos projetos de que participa. É certo que tal situação está incorporada nas estratégias tecnicistas de planejamento adotadas nas instituições. Esta visão fragmentada não decorre apenas da multidisciplinaridade do conhecimento envolvido. Decorre, sobretudo, da divisão do trabalho técnico-científico, levada aos extremos, maximizada pela ausência de um método que "ilumine" cada ação compartimentada. Assim sendo, nesta situação indesejável, os técnicos podem controlar apenas as suas tarefas imediatas e, quando é possível, no máximo as de seu setor. Transformam-se em meros cumpridores de recomendações ou reprodutores de comportamentos técnicos já consolidados pela instituição de que fazem parte. $\mathrm{O}$ fato conduz à cristalização de posturas equivocadas. O sujeito "planejador" sente-se desmotivado e destituído da visão crítica e criativa, na sensação ilusória - reforçada pelo meio que o circunda - de que este seja o único papel que lhe destina.
} 
predominante no que poderia ser chamado de governo urbano. As concepções tecnocráticas, chamando para si a responsabilidade de moldar os planos em gabinetes fechados, terminam por encontrar o vazio. Os planos são esterilizados em sua concepção, destituídos de legitimidade social. O discurso oficial, de que planos são para todos, é contrariado na prática 25 . A "consulta" às populações sobre as decisões não pode ser tomada como participação efetiva. O envolvimento coletivo nas decisões é parte de um processo relativamente lento, que pode obter maior ou menor expressividade dadas as especificidades das localidades: demanda uma conscientização política dos habitantes; implica em educação e espírito de parceria e de solidariedade. Os planos, também sob esse aspecto, somente têm significado quando respondem às aspirações coletivas. A transformação de ambientes sócio-espaciais, estabelecidos e discutidos os rumos da mudança, é reflexo da mobilização de seus habitantes: mobilização pela consciência da necessidade de mudar. Somente assim os planos podem cumprir seus papéis e suas promessas: instrumentos pedagógicos de uma transformação tomada como necessária; instrumentos democráticos das localidades.

Qual o conteúdo das observações? O sentido concreto da ciência encontra-se fora dela. Ao se pensar o planejamento como política e como a dimensão da ciência aplicada, necessariamente há de se refletir sobre uma pedagogia do planejamento. As comunidades que participam dos planos, por mais distantes que se encontram das decisões, devem ser entendidas como a única motivação das estratégias. Os indivíduos construíram entendimentos da realidade que são provenientes de uma prática social concreta. É para eles que os planos devem ser construídos: para que aperfeiçoem sua prática. Para tanto, o planejador deveria ser aquele que, por ser "porta-voz" da ciência, também ensina a aprender - aprendendo - como se planeja. Do mesmo modo, o planejador seria aquele a potencializar sensibilidades, reconstruindo a sua própria sensibilidade. O planejador seria aquele que, "falando", faz a cidade falar consigo mesma: através da rua e dos bairros, através das pequenas comunidades. Do mesmo modo, e pelo mesmo motivo, o planejador seria também aquele que, ouvindo, faz com que a cidade tenha a oportunidade de construir o seu discurso próprio e compatível com a sua história.

\section{BIBLIOGRAFIA}

AB' SÁBER, A. N. “Geografia e planejamento”. In: Geografia e Planejamento. São Paulo: Instituto de Geografia da Universidade de São Paulo, 1969. p. 11-26.

BERNARDES, N. "A Geografia e o planejamento regional”. In: Geografia e Planejamento. São Paulo: Instituto de Geografia da Universidade de São Paulo, 1969. p. 1-4.

BRONOWSKI, J. O senso comum da ciência. Belo Horizonte: Itatiaia; São Paulo: Editora da Universidade de São Paulo, 1997.

CASTELLS, M. \& BORJA, J. "As cidades como atores políticos". In: Novos Estudos CEBRAP. N. ${ }^{\circ}$ 45. São Paulo: CEBRAP, jun. 1996. p. $152-166$.

CERON, A. O. \& GERARDI, L. H. O. “Bases geográficas para o planejamento rural no Estado de São Paulo”. In: Geografia. v. 6. N. 11-12. Rio Claro: AGETEO, out. 1981. p. 105-159.

CLARK, D.Introdução à Geografia Urbana. São Paulo: Difel, 1985.

CORAGGIO, J. L. "Possibilidades de um planejamento territorial para a transição na América Latina”. In: Espaço e Debates. $\mathrm{N}^{\circ}$ 20. São Paulo: NERU, 1987. p. 63-94.

FERREIRA, F. W. Planejamento sim e não: um modo de agir num mundo em permanente mudança. 10 ed. São Paulo: Paz e Terra, 1988.

GOMES, H. “Geografia e planejamento”. In: Boletim Paulista de Geografia. № 61. São Paulo: AGB, $2^{\circ}$ semestre 1984. p. 119-131.

GUIDUGLI, O. S. "Geografia e Planejamento: problemas e perspectivas de interface”. In: Geografia. v. 5. N. 9-10. Rio Claro: AGETEO, 1980. p. 1-18.

GUIGOU, Jean-Louis. "A terra e o espaço: enigmas para os economistas”. In: SANTOS, M. \& SOUZA, M. A. A. de. $\boldsymbol{O}$ Espaço Interdisciplinar. São Paulo: Nobel, 1986. p. 105-132.

LA BLACHE, P. V. de. "As características próprias da Geografia”. In: CHRISTOFOLETTI, A. (org.). Perspectivas da Geografia. São Paulo: Difel, 1982. p. 37-47.

MATUS, C. Adiós, señor presidente: planificación, antiplanificación y gobierno. Caracas: Pomaire / Ensayos, 1987.

MATUS, C. "Fundamentos da planificação situacional". In: RIVERA, F. J. U. (org.). Planejamento e Programação em Saúde: um enfoque estratégico. São Paulo: Cortez, 1989. p. 107-123.

MELO, M. L. de. "Nordeste, planejamento e Geografia". In Geografia e Planejamento. São Paulo: Instituto de Geografia da Universidade de São Paulo, 1969. p. 5-10.

PAVIANI, A. "Geógrafo em atividade de planejamento urbano: 'projeto Águas Claras', Distrito Federal”. In: Geografia. v. 9. N. 17-18. Rio Claro: AGETEO, out. 1984. p. 81-100.

RESENDE, V. Planejamento urbano e ideologia: quatro planos para a cidade do Rio de Janeiro. Rio de Janeiro: Civilização Brasileira, 1982.

SANTOS, B. de S. Introdução a uma ciência pós-moderna. Rio de Janeiro: Graal, 1989.

SÃO PAULO (Estado). Secretaria de Estado do Meio Ambiente. Política Municipal de Meio Ambiente: orientação para os municípios. 2 ed. São Paulo: Centro de Estudos e Pesquisas em Administração Municipal / CEPAM, 1992.

VELOSO, M. E. de L. "O geógrafo e a futura série ISO 14.000”. In: PEDROSO, N. G. (org.). Geógrafos: legislação, formação e mercado de trabalho. São Paulo: Associação dos Geógrafos Brasileiros / Conselho Federal de Engenharia, Arquitetura e Agronomia, 1996. p. 37-50.

25 - "Sem dúvida, é tarefa dos governos locais pensar novas formas de desenvolvimento, questionando o progresso desejável e dando prioridade aos investimentos sociais nas áreas de educação, nos serviços de atendimento à saúde, transporte, habitação, saneamento básico, proteção ao meio ambiente, combate à poluição e à erradicação da pobreza, promovendo a discussão dos objetivos e diretrizes na formulação das políticas públicas municipais" (SÃO PAULO, 1992: 34). 